\title{
A brief reeducation in cardiopulmonary resuscitation after six months-the benefit from timely repetition
}

VEDRAN FRKOVIĆ $(\bowtie) \cdot$ ALAN ŠUSTIĆ • FRED ZEIDLER •

ALEN PROTIĆ • KRISTIAN DEŠA

Department of Anesthesiology, Reanimatology and Intensive Care Medicine, Rijeka University Hospital, School of Medicine, Rijeka, Croatia T. Strizica 3, 51000 Rijeka, Croatia Phone: + 385981873973 Fax: +38551218407

E-mail: Vedran.Frkovic@ri.htnet.hr

\author{
VEDRAN FRKOVIĆ • ALAN ŠUSTIĆ • FRED ZEIDLER • \\ ALEN PROTIĆ • KRISTIAN DEŠA
}

\begin{abstract}
Objectives. Sudden cardiac death is a major cause of death in today's world. During the minutes passing from the onset of cardiac arrest to the arrival of professional help, the cardiac arrest victim can only rely upon cardio-pulmonary resuscitation (CPR) provided by educated bystanders. Our aim was to explore the possibility of whether a short and affordable course of $C P R$ reeducation could have a significant effect on skills retention and quality of CPR delivered.

Methods. We performed a prospective randomized study that included 72 first and second year medical students who had no clinical experience and no prior training in CPR. Subjects were educated in CPR in accordance with a standardized CPR education protocol. Six months later, half of the studied group (randomly chosen) underwent short reeducation in CPR. One year after initial education they were all tested for CPR skills. The results were printed and filmed.

Results. Students who attended the short reeducation were significantly better in approaching the victim safely, in obtaining a clear airway and in checking the pulse of the victim.

Conclusions. A short and inexpensive course of reeducation, carried out six months after initial education, may render CPR performance more effective for the victim and safer for the rescuer.
\end{abstract}

Key words: medical education, resuscitation, medical students, basic life support

\section{Introduction}

Sudden cardiac death is a major cause of death in today's developed countries. (1) A common mechanism of cardiac arrest causing sudden cardiac death is the onset of ventricular fibrillation (1) in patients suffering underlying cardiac disease. In most cases, defibrillation and other means of advanced life support are not immediately available. In urban settings it takes an average of nearly ten minutes for professional help to arrive. (2) During this time victims can only rely upon cardiopulmo- nary resuscitation (CPR), provided by educated bystanders. (2) Therefore, a substantial burden of responsibility lies on the shoulders of educators who need to pass on their knowledge and skills of CPR to their trainees in a way simple enough to be remembered and recalled rapidly in a highly stressful moment. (3) It has been shown that correctly performed bystander CPR may positively influence short and long-term survival of cardiac arrest victims. $(3,4)$ Eventhough CPReducation has evolved since its beginnings, many problems remain. Several authors described the problem of poor performance in CPR, even when provided by medical professionals. (5) Numerous investi- gations have reported the problem of poor skills retention after various CPR courses. $(6,7)$ Studies reporting the need for improvement of resuscitation techniques led to the recent changes in BLS and ALS algorithms. (8) Proposed changes should result in simpler and thus more effective teaching, learning and performance of CPR. (8) An underlying cardiac condition is not the only possible cause of cardiac arrest. Cardiac arrest may also be caused by electrocution, poisoning, trauma etc. These types of cardiac arrest occur mainly in out- of -hospital settings, in various adverse situations. $(9,10)$ All of these situations represent a substantial risk for the rescuer and there is a risk of 
rescuer casualties when trying to help these victims, when adequate precautions are not met. (10) The possibility of rescuers getting hurt when trying to save a victim warns us not to neglect rescuers' safety when teaching CPR.

There are two ways we can try to improve skills retention: by simplifying CPR courses or by reeducating trainees. It has been reported that simplification of training results in easier learning but it is unlikely to substantially improve skills retention. (11) While reeducation may be time and money consuming unless specifically designed to be short and inexpensive. It has been shown that it is needed to develop targeted programs to make CPR trainees maintain their CPR skills. (12)

Our aim was to explore the possibility of whether a short and affordable course of CPR reeducation could have a significant effect on skills retention and quality of CPR delivered. In our research we focused on medical students in the first years of their education as individuals who are most likely to encounter situations in which they may need to perform CPR as today's educated bystanders or medical professionals of the future.

\section{Methods}

A prospective randomized study was undertaken during a one year period from November 2004 to November 2005. A total of 72 first and second year medical students from the University of Rijeka School of Medicine were included in our research. First and second year students represent an adequate bystander population since they do not have any clinical experience. Inclusion criteria for the study were first year medical students, who had no prior training in CPR, and attending obligatory training in First aid. The study was designed to be carried out in three phases: 1 . Initial education, 2. Short reeducation after six months and 3. Testing and analysis of results one year after initial education.

Initial education: During First aid classes all 72 participating students were educated in CPR according to European Resuscitation Council standards. Train- ing was provided by two certified ERC instructors. All students had attended a lecture on basic life support after which they were divided into workgroups containing no more than four students per instructor. Instructors used the ERC standard four step approach to teaching CPR (13) where the first step consisted of a demonstration by instructors of real time CPR performed according to an algorithm but with no explanations. The second step consisted of a demonstration by instructors of CPR performed according to an algorithm with the instructor explaining particular steps of algorithm. The third step consisted of each student guiding and explaining the procedure to the instructor, so that each skill is correctly performed, and by doing so applying „re-enforcement of good practice". (13) The fourth and final step involved the students practicing CPR, according to the algorithm, during which students took turns performing CPR on manikins. Each student was required to perform at least three series of complete CPR lasting at least two minutes per series. After education all students were randomly assigned to one of two equal groups containing 36 students each. Randomization was carried out in a way that students blindly pulled papers with the number (1 or 2) of the pertaining group from a box.

Shortreeducation: Sixmonths after initial education the first group of 36 students was required to attend a short session of reeducation in CPR. The same two instructors who first taught the students conducted reeducation. Students were again divided into workgroups containing no more than four students per instructor. This time instructors briefly reminded students of the key points of the CPR algorithm. Subsequently, students were required to perform two series of complete CPR until they performed four cycles of ventilations and compressions in each series. The short reeducation took no more than 20 minutes per student workgroup.

Testing and comparison: One year after initial education and six months after the short reeducation of half of the students, the second year medi- cal students attended an 'Introduction to emergency medicine' class. Both groups (reeducated and non-reeducated) were evaluated in their CPR performance. The evaluation was undertaken by analyzing manikin printouts and video recordings of testing. Evaluation of students was scenario based. Students were offered a scenario of a middle- aged man suffering from a cardiac arrest in the street. After entering the examination room, with a manikin on the floor, every student was told: "While walking down the street you encounter a fifty five year old male lying on the sidewalk. Please show us how you would proceed in that situation." Initially the manikin was unresponsive, apnoeic and pulseless. Each student was expected to exhibit the complete algorithm of CPR. After four cycles of mouth-to-mouth ventilations and cardiac compressions each student was asked to stop CPR and check for a carotid pulse again.

The parameters that were subject to assessment were: safe approach, call for help from surroundings, opening of the airway, breathing check, call for ambulance, pulse check, adequacy of inspired volume in mouth to mouth massage (500-1000 ml), inflation of the stomach (present/absent), adequacy of chest compressions (80-120/min acceptable with proper hand positioning, 38-51 mm depth) and ventilationcompression ratio (2:15 at the time). All parameters were assessed in accordance with the European Resuscitation Council BLS guidelines valid at the time our research was conducted. (14) Initial education, short reeducation and testing were performed using Laerdal Resusci®Anne SkillReporter ${ }^{\mathrm{TM}}$ manikin for CPR. (Laerdal Medical, København, Denmark).

There were few variables that couldn't be assessed by manikin printouts (clearly demonstrated safe approach, unambiguous calls for help, adequate head tilt-chin lift, satisfactory breathing check). To objectively asses the afore mentioned potentially subjective variables, students were filmed and the footage was subject to the joint 
assessment of two other instructors participating in this study whose only task was to review and assess together video footages independently from the instructors providing the initial education and reeducation. Before assessing the tapes, the reviewers agreed on a standard of assessment beforehand. A safe approach was considered to be safe when the student looked around himself/herself searching for a possible threat and clearly stated that the surroundings were safe. Head tilt was considered to be adequate when performed using both hands to tilt and lift the chin to pull the obstructing tongue out of throat, in accordance with the technique described in the ALS provider manual. (13) Breathing check was considered to be satisfactory when performed so as to enable "listen, see and feel the breath" for ten seconds.

Our study was blinded to instructors i.e. two instructors, other than those providing initial education and reeducation, reviewed the tapes of the final CPR testing. However, a limitation might be the fact that we did not observe inter-rater and intra-rater variability when assessing the tapes.

Statistical analysis was carried out using the statistical software Statistica 6.0 (Stat.Inc., USA). Comparison between the groups was made using Mann-Whitney $U$ test. The results were considered to be statistically significant when $\mathrm{P}<0.05$ was found.

\section{Results}

Results are shown in table 1. The accuracy of procedures undertaken by students was assessed in comparison to ERC BLS guidelines effective at the time of our study. (14) We analyzed twelve variables of key importance in delivery of a complete sequence of basic life support. When comparing reeducated and non-reeducated groups of students we have found statistically significant differences in three of them.
Among students who performed an adequate safe approach, there were a significantly higher number of students who attended the short reeducation six months after initial CPR education $(P=0.005)$. Head tilt/chin lift maneuver was statistically significant and better performed by reeducated students as well $(P=0.018)$.

Reeducated students were also significantly more accurate than non- reeducated students when pulse check was analyzed $(P=0.002)$.

\section{Discussion}

Our research is in accordance with numerous previous studies that show rapid and significant skill deterioration among CPR trainees. $(11,15)$ We have found that skills of our non -reeducated students declined severely during a one year period.

The problem of skills deterioration might partially be solved by recent changes in CPR guidelines (8) which

Table 1. Comparison of differences in cardiopulmonary resuscitation (CPR) performance one year after initial CPR education between students who attended brief reeducation six months after initial CPR education and non-reeducated students. The numbers relate to correct performance.

\begin{tabular}{|c|c|c|c|}
\hline & Reeducated $(n=30)$ & $\begin{array}{l}\text { Non-reeducated }(n=33) \\
N(\%)\end{array}$ & $\begin{array}{l}P \text { value } \\
N(\%)\end{array}$ \\
\hline Safe approach & $28(93)$ & $21(64)$ & 0.005 \\
\hline Call for help & $30(100)$ & $32(97)$ & NS \\
\hline $\begin{array}{l}\text { Open and check airway } \\
\text { (head tilt/ chin lift maneuver) }\end{array}$ & $28(93)$ & $23(69)$ & 0.018 \\
\hline Check breathing & $29(97)$ & $31(94)$ & NS \\
\hline Call for ambulance & $28(93)$ & $30(91)$ & NS \\
\hline Adequate ventilation volume & $16(53)$ & $12(36)$ & NS \\
\hline Inflation of stomach & $7(23)$ & $6(18)$ & NS \\
\hline Pulse check & $25(83)$ & $15(45)$ & 0.002 \\
\hline Adequate chest compressions & $25(83)$ & $27(82)$ & NS \\
\hline $\begin{array}{l}\text { Adequate rhythm of chest } \\
\text { compressions }\end{array}$ & $22(73)$ & $25(76)$ & NS \\
\hline $\begin{array}{l}\text { Adequate ventilation-compression } \\
\text { ratio }\end{array}$ & $29(97)$ & $28(85)$ & NS \\
\hline
\end{tabular}

NS, non -significant. 
should render CPR simpler and more effective. Omission of the pulse checking procedure from the CPR algorithm should minimize time losses bound to that procedure which had been of dubious benefit due to its unreliability and time consumption, no matter had it been performed by healthcare professionals or by educated bystanders. $(16,17)$ Our results are in favor of such changes. Whereas $83 \%$ of reeducated students were able to check for the pulse properly, which may seem an encouraging number, the fact that in a one year period, the number of non -reeducated students who were able to perform accurate puls check declined below a mere $50 \%$, is disappointing. Such a drop might suggest that when it comes to pulse checking, the rapid time related loss of skills surpasses possible gain obtained by reeducation. Rescuer safety is the first and arguably most important point of the whole procedure of CPR. Failure to insist on personal safety of the rescuer may result in serious injuries or even death of the rescuer, thus making two certain victims instead of one possible. The importance of emphasizing a safe approach in performing CPR is of no less importance when teaching CPR to future medical professionals than to bystanders. Many medical students will be working in out- of- hospital settings in an uncontrolled environment where they might be exposed to a wide spectrum of risks when trying to help the cardiac arrest victim, (10) meeting the same risks as a regular bystander. It has been shown that bystanders who underwent CPR retraining are highly motivated to help cardiac arrest victims. $(18,19)$ Their motivation in conjuncture with the intensity of the atmosphere surrounding the situation of attempted resuscitation might induce them to neglect their own safety. In our study we have shown that in the reeducated group only $7 \%$ of trainees fail to check safety of the setting whilst in the nonreeducated group a substantial 36\% fail to do so. Opening of the airway is probably the crucial maneuver when it comes to ventilating a non-breathing person. In most cases proper head tilt/ chin lift frees the airway of the obstructing tongue and makes efficient ventilation possible. (20) Skill deterioration of airway opening was not as dramatic as the decline in pulse checking. It is reflected in the $31 \%$ of non-reeducated students who were unable to perform an effective chin lift/head tilt vs. only $7 \%$ of reeducated ones suggesting that this skill might be among skills that could be improved to last longer by short retraining six months after initial education.

The problem of poor CPR performance itself or as a part of ALS is well described in the literature. $(5,21)$ Some authors claim that changes in resuscitation guidelines over the course of the last two decades have not made much difference to the survival of patients and that even in ALS there should be more attention focused on more basic procedures such as CPR. (2) Obviously, there is room for improvement even when it comes to the simple procedure of CPR. We believe that it would be useful if future investigations would be oriented towards trying to find the best possible way to modify the brief reeducation so that final CPR knowledge becomes even more valuable.

None of the authors have any conflict of interest regarding this research.

\section{Conclusions}

In light of our findings we might conclude that a short and inexpensive course of reeducation, carried out six months after initial education, may render CPR performance more efficient for the victim and safer for the rescuer.

\section{REFERENCES}

1. Podrid PJ, Myerburg RJ. Epidemiology and stratification of risk for sudden cardiac death. Clin Cardiol 2005;28(11 Suppl 1):11-3.

2. Sanders AB, Ewy GA. Cardiopulmonary resuscitation in the real world: when will the guidelines get the message? JAMA 2005;293(3):363-5.

3. Vukmir RB. Witnessed arrest, but not delayed bystander cardiopulmonary resuscitation improves prehospital cardiac arrest survival. Resuscitation 2006;69(2):229-34.

4. Gallagher EJ, Lombardi G, Gennis P. Effectiveness of bystander cardiopulmonary resuscitation and survival following out-of-hospital cardiac arrest. JAMA 1995;274(24):1922-5.

5. Hendry JM. Poor Quality CPR Often Performed by Trained Medical Professionals. Available from: http://www.merginet.com/index. cfm?searched=/clinical/cardiac/PoorQualityCPR.cfm. Accessed: November 18. 2006.

6. Chamberlain D, Smith A, Woollard M, Colquhoun M, Handley AJ, Leaves S, et al. Trials of teaching methods in basic life support (3): comparison of simulated CPR performance after first training and at 6 months, with a note on the value of re-training. Resuscitation 2002;53(2):179-87.

7. Donnelly P, Assar D, Lester C. A comparison of manikin CPR performance by lay persons trained in three variations of basic life support guidelines. Resuscitation 2000;45(3):195-9.

8. Handley AJ, Koster R, Monsieurs K, Perkins GD, Sian D, Bossaert L. European Resuscitation Council Guidelines for Resuscitation 2005 Section 2. Adult basic life support and use of automated external defibrillators Resuscitation 2005;67 Suppl 1:S7-23.

9. Ornato JP. Special resuscitation situations: near drowning, traumatic injury, electric shock, and hypothermia. Circulation 1986;74(6 Pt 2): IV23-6. 
10. Kloeck W, Cummins RO, Chamberlain D, Bossaert L, Callanan V, Carli P, et al. Special resuscitation situations: an advisory statement from the International Liaison Committee on Resuscitation. Circulation 1997;95(8):2196-210.

11. Hamilton R. Nurses' knowledge and skill retention following cardiopulmonary resuscitation training: a review of the literature. $\underline{J \text { Adv Nurs }}$ 2005;51(3):288-97.

12. Riegel B, Birnbaum A, Aufderheide TP, Thode HC Jr, Henry MC, Van Ottingham L, et al. PAD investigators. Predictors of cardiopulmonary resuscitation and automated external defibrillator skill retention. Am Heart J 2005;150:927-32.

13. Group of authors. The skill teaching algorithm in four stages. In: Bullock I, Colquhoun M, editors. Generic instructor course. Advanced life support instructor manual. Rochester (UK): Resuscitation Council (UK) and European Resuscitation Council (ERC); 2001. p. 25-6.

14. Handley AJ, Monsieurs KG, Bossaert LL. European Resuscitation Council Guidelines 2000 for Adult Basic Life Support. Resuscitation 2001;48(3):199-205.

15. Kaye W, Rallis SF, Mancini ME, Linhares KC, Angell ML, Donovan DS, et al. The problem of poor retention of cardiopulmonary resuscitation skills may lie with the instructor, not the learner or the curriculum. Resuscitation 1991;21(1):67-87.

16. Flesche CW, Zucker TP, Lorenz C, Neruda B, Tarnow J. The carotid pulse check as a diagnostic tool to assess pulselessness during adult basic life support. Euroanesthesia 1995;95:72. Abstract.

17. Bahr J, Klingler H, Panzer W, Rode H, Kettler D. Skills of lay people in checking the carotid pulse. Resuscitation 1997;35(1):23-6.

18. Lester CA, Donnelly PD, Assar D. Lay CPR trainees: retraining, confidence and willingness to attempt resuscitation 4 years after training. Resuscitation 2000;45(2):77-82.

19. Axelsson A, Thoren A, Holmberg S, Herlitz J. Attitudes of trained Swedish lay rescuers toward CPR performance in an emergency. A survey of 1012 recently trained CPR rescuers. Resuscitation 2000;44(1):27-36.

20. Koh KF. Clinical update on managing the obstructed airway. Annals of the Academy of Medicine, Singapore. 2002;31(2):253-6.

21. Axelsson A, Herlitz J, Fridlund B. How bystanders perceive their cardiopulmonary resuscitation intervention; a qualitative study. Resuscitation 2000;47(1):71-81. 